\title{
A Cognitive Approach to the Development of Human Resources for New Entrepreneurship Types of Market Foresight Demand
}

\author{
Anna.V. Shokhnekh \\ Volgograd State Socio-Pedagogical University \\ Volgograd, Russia \\ shokhnekh@yandex.ru
}

\author{
Victoria S. Telyatnikova \\ Volgograd State Socio-Pedagogical University \\ vika.t@list.ru
}

\author{
Elena Yu. Marusinina \\ Volgograd State University \\ Volgograd, Russia \\ nmushketova@yandex.ru
}

\begin{abstract}
The development of human resources in order to be prepared for new types of entrepreneurship is based on understanding of social and personal significance. To conduct entrepreneurial activity, a combination of a number of personality qualities is necessary. It creates the basis for the successful achievement of a complex goal. The article presents the key determinants of the motivational component of the individual to entrepreneurial activity, economic routine of supply subjects in a cognitive approach and psychological analysis of new types of entrepreneurial activity. In fact, the causal attribution based on observations of the other people's behavior was investigated and it was explored that it is based on the desire to recognize its driving forces, such as motives, intentions, goals, anxiety.
\end{abstract}

Keywords: a cognitive approach, to the development, human resources, new entrepreneurship types, demand

\section{INTRODUCTION}

The concept of human resources being psychologically ready for doing business as the foundation of Russia's economic well-being is based on the concept of "entrepreneurship", "being ready for entrepreneurship." The key factor in the entrepreneurial intentions of the individual is to become a private need for independence. However, ensuring personal security conditions also becomes one of personal needs. Safety at work as well as freedom of action is an existential need of a person. So Erich Fromm defined two categories that prompt a person to act: 1) the need for freedom; 2) security needs. A person always balances between the pursuits of freedom and security, which determine a powerful motivational force in human life.
To solve problems in the development of human resources, it is proposed to study key indicators from the standpoint of the principle of determinism. Determinism as a doctrine of the relationship and interdependence of the phenomena of reality defines: 1) the causes and laws of the interaction of society with nature; 2) the driving forces of social development; 3 ) processes the impact of society on moral standards; 4) areas of scientific development and art in society; 5) routes of formation and human activities [17, 19].

A cognitive approach to the study of new types of entrepreneurship to ensure market foresight demand involves the study of the heredity determinant, which reproduces in biological descendants similar to parents at birth [18]. The essential properties are those that distinguish one person from another, which confirms the individual genetic fixations that determine the anatomical and physiological predisposition to various types of activity in economic life. Anatomical and physiological predispositions like these are called inclinations.

\section{LITERATURE OVERVIEW}

However, the study shows that the fixed genetic properties are only general initial prerequisites for the further development of man, which in the process of social life are shown as individual psychological characteristics of the person, ensuring the successful performance of labor activity [2]. One of the types of labor activity is entrepreneurial 
activity. Entrepreneurship is associated with the provision of services and the production of goods for profit in the face of uncertainty and economic risk. In conditions of the need to make their own decisions, an entrepreneurial as a business active person is associated with an independent disposal of material and human resources [11, 22]. Also, according to other authors, entrepreneurial activity is not only profitmaking activity, but also the activity of managing public organizations and state institutions $[8,16]$.

The study shows that in order to conduct business activity, a number of personality traits is necessary, which creates the basis for the successful achievement of a complex goal.

The combination of qualities that allows you to be a successful person in any activity, including entrepreneurial, is a gift. A high degree of being gifted is classified as talent, and the highest as genius [2].

Entrepreneurship is correlated with the special personality characteristics of its subject. It shows the immanent nature of entrepreneurship: the behavioral dominant of initiative, innovation and risk in economic activity $[4,5,15,21]$.

An interesting point of view is that the distinguishing feature of entrepreneurship is not the ability to end a routine and create something new, but the ability to see opportunities unnoticed by others [7]. It should be noted debatability and ambiguity in understanding the essence of the definition of "entrepreneurship" and "business". The study shows that the identification of these concepts does not correspond to their semantic meaning [13].

Entrepreneurship, which has features common to business (production, consumption, exchange, profit, etc.), has specific features that are different from reproductive options: innovation, which involves new results, high risk, personal responsibility[20]. Entrepreneurship acts as an element of a business system, is a multi-system entity, including entrepreneurship and intrapreneurship as components [9]. The study shows that entrepreneurship has wider boundaries of essential understanding, including the development of new projects, ideas and technologies, which allows creating new products that have not only monetary value, but also social value.

Therefore, the result of entrepreneurial activity is manifested in the creation (invention) of new business forms, where the entrepreneurial subject becomes a fashion designer in the design and practice of the individual to create new sources of material resources, which is carried out at risk [10].

\section{MATERIALS AND METHODS}

Psychological analysis shows that a positive experience from the process of completing work is compensated for by such a phenomenon as "self-reward" for fulfilling a public mission and achieving difficult goals. The entrepreneur's behavior is realized in conditions of "unwarranted", "nonequivalent" or asymmetric exchange. In particular, $\mathrm{H}$. Hekhausen, argues that it is difficult to determine personal contribution (exchange) in such cases by the quantitative incomparability of personal parameters, the individuality and uniqueness of personal meanings and the interchangeability of individual needs [6].

Limitations of the framework of economic models were established in both domestic and foreign sociology, where the behavior of isolated individuals is not limited to economic goals. So, V. Radaev distinguishes the "compromise" sociological model, which removes the limitations of the interpretation of man as homo oeconomico (selfish, independent, rational and informed) or homo socialis (altruistic, subordinate to society, behaving irrationally) is the model "socio-economic man" [12].

Therefore, A. Zhuravlev and A. Kupreichenko suggest "value-rational rationality" as the most general regulator of the economic activity of the individual as a paradox of the economic activity of the individual from the position of a reflecting, independent and responsible subject.

It should be noted that entrepreneurship is based on ethnoconfessional, cultural and historical traditions and its social type, determined by a specific culture. It is stable only in its general environment. The size of the organizational model of the entrepreneurial also becomes the basic characteristic of being ready to involve a certain number of people (where small, medium and large entrepreneurship are distinguished). It determines the acceptance of voluntary personal responsibility for himself/herself, his/her business, for his/her employees and their living conditions.

Also, the personal perception of the possibility of doing business implies that the entrepreneurial cannot be in the "comfort zone" in view of the complexity and risky specific activity. The absence of a "comfort zone" is manifested in a high level of responsibility, which determines constant anxiety to break the rules. In the concept of preparing human resources for doing business, the principles of a positive emotional attitude through a motivational-value component should be established.

\section{RESUlts}

The study shows that the motivational component to the entrepreneurial activity of an individual can manifest itself through eight key determinants: 1) the personal determinant "self" is a request for personal self-determination for the free adoption of exclusively independent decisions, an absolute "self" in the implementation of one's own projects; 2) the personal determinant of "leadership" is the request of the individual for power through the subordination of employees to team decisions; 3 ) the social determinant "missionary" is a person's perception of society's requests for a high-quality and high standard of living of the population; 4) the determinant of the "social and economic mission" is the suppression of the social demand of society and the economic demand of the individual at points of high interest; 5) economic determinant is personal initiatives to act through the exchange function in proportion to the effort and financial costs that are equated to compensated labor costs; 6) mental determinant is mental perceptions by a person of routes to ensure a high-quality and high standard of living of a society through the influence of their own management decisions; 7) the cognitive determinant is sustainable personality map- 
in the main functions: 1) the adoption of information; 2) processing and analysis of incoming data; 3) the formation of the information core for decision making; 4) decision making process; 5) implementation of the decision; 6) analysis of the results of the decision; 7) adjustment of subsequent actions.

The study shows that a person can be born with an inclination of a leader, but whether he will be a middle or senior manager as an employee, or organize his own business in the form of small, medium and large business depends on many factors surrounding him. The process of formation and development of personal internal determinants correlates with the conditions of his life in society and the external environment. Where it is customary to classify the factors of the external environment such as geographical, social environment, upbringing, traditions, national culture, religion. In any case, the choice of new types of entrepreneurial activity will be made in the field of a particular person's cognitive and mental understanding of reality.

The external dominant will be the popularization of entrepreneurship. Popularization will play a key role in the process of preparing human resources for the choice of entrepreneurial activity. Obviously, respect in the family, school, and the media for entrepreneurial activity as a social phenomenon will raise credibility and also form an understanding of the level of responsibility in the structure of management and decision-making. The cognitive approach to the study of the development of human resources made it possible to apply the causal attribution method in the selection of new types of entrepreneurship to ensure market foresight demand.

Application of the psychic projection of consumer behavior in a cognitive economy from the perspective of causal attribution of "subjects of supply" is a relevant research topic in the conditions of turbulence in the external environment, which determines the sequence of economic crises. The relevance of long-term forecasting from the perspective of the "subjects of supply" is dictated by the limited resources of production, the direction of the world economy towards "sustainable development". Sustainable development of the world and national economies is aimed at: 1) the growth of GDP indicators; 2) restoration of the ecological balance; 3) replenishment of exhaustive resources; 4) the search for deep processing and modification technologies. In 1987 G. Brutland spoke at the UN General Assembly at the Commission on the Environment and Development for the first time from this point of economic development. This approach has caused a lot of controversy and discussion. However, the concept of «sustainable development» has evolved, and today it is interpreted as «long-term continuous development, providing the needs of people living today without compromising the needs of future generations» [1].

In case of the sustainable development, the transformation of the economy covers both the mental basis of the producer and the consumer. Under such conditions economic theory begins to evolve on the platform of a cognitive approach.

New definitions appear in economic terms which attract attention from the perspective of academic transformations
Fig. 1. Key determinants of the motivational component of the individual to entrepreneurial activity

It means that the development of human resources in order to be prepared for new types of entrepreneurship is based on understanding of social and personal significance, manifested 
possibility: «behavioral economics»; «Cognitive economy»; «Cognitive map of entrepreneurship development»; «Neuro analysis decision making in management» and so on. The transition to a cognitive economy is accelerating in the expansion of new global digitalization trends. Sustainable development determines the vision of the world economic system in 30-35 years using foresight methods. The identification of negative productions of «subjects of supply» for «subjects of consumption of goods» requires new methods of mental projection of consumer behavior. However, one can give a different assessment of this approach from the standpoint of the social and economic development of the population, aimed at improving the welfare and quality of life of society. Here we can denote anxieties regarding the mastery of manipulations that will allow one to receive benefits due to the deterioration of the condition of others [23, 25]. From the position of rational and fair distribution, as basic principles of economics, today it is necessary to apply the theory and methodology of cognitive economics. As an example, one can cite many achievements of world science, which became the basis for a quantum leap in the development of civilization, but were also used for anti-human purposes like photo effects, nuclear energy. The laws of the cognitive approach have long been attracted by marketing, which helps to make both social advertising and advertising that allows people to be manipulated. For the manufacturer, demand is always important, which can be investigated on the basis of cognitive technologies. The value of understanding demand is critical to the success of the producer of goods. But today production is becoming a common problem in terms of the lack of resources [24]. Any simple or complex process of creating benefits for the consumer always has a multi-stage structure: genesis, analysis, project, investment, financial consumption, processing of resources (resource consumption), formation of a consumption product, implementation process, financial recovery, control of production routine, analysis of control results, The economic routine of the subject of supply is presented in Figure 2.

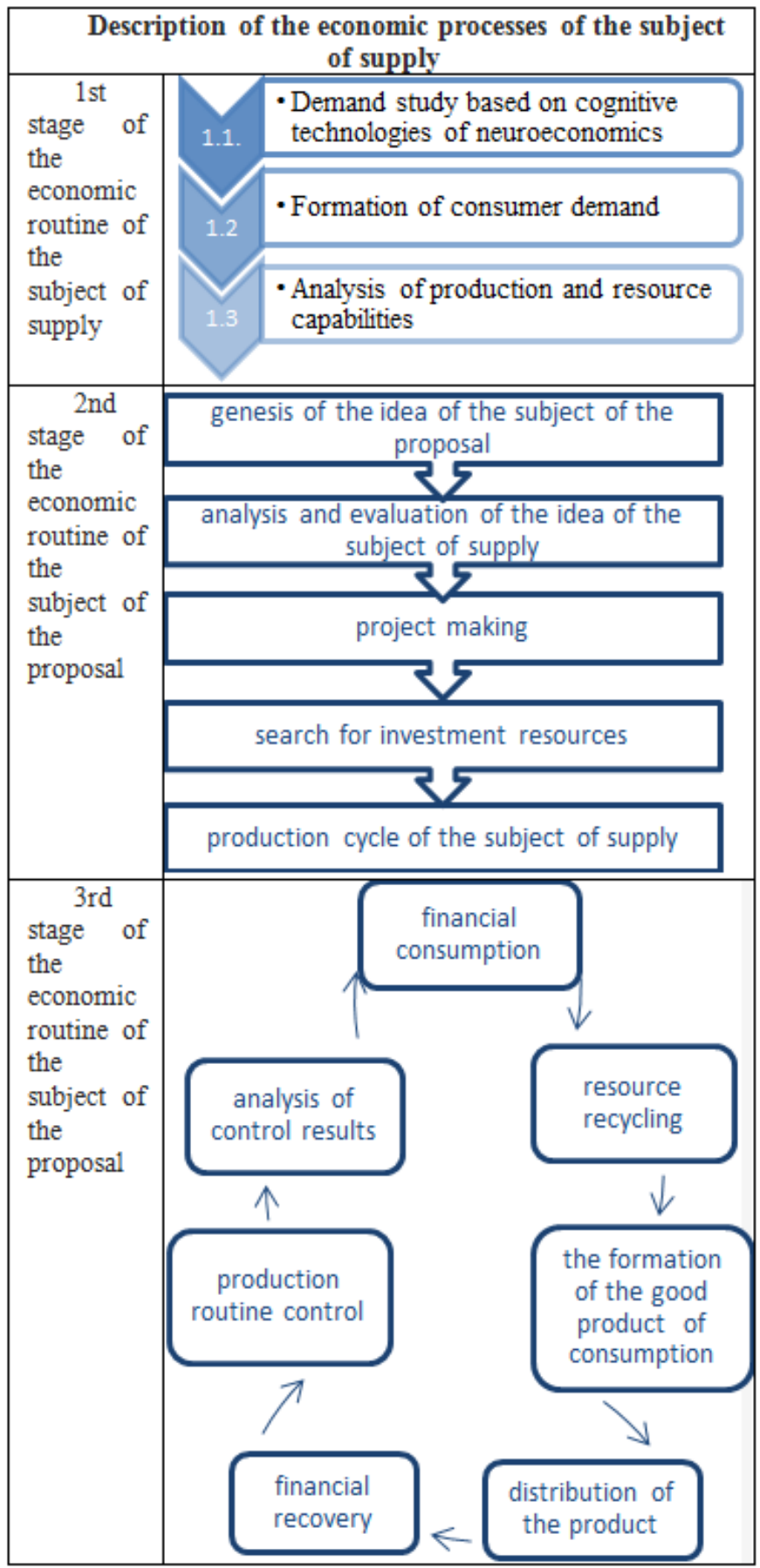

Fig. 2. Economic routine of supply subjects in a cognitive approach

With the production process the subjects of the supply are mostly defined and studied. There is always a degree of uncertainty in the behavior of the subject of consumption of goods. All needs are reduced to the provision of basic desires for human life. Studies show that today there are needs that contradict this theory. For example, providing the need to have a slim figure causes anorexia, and as a result, the rejection of all the necessary products for life.

A cognitive map, while clearly enshrined in the minds of consumers, can distort a person's natural needs at a 
psychological level. Today it is important to determine the factors influencing the decisions of consumers to use this or that benefit. Causal attribution based on observation of another's behavior is built on the desire to recognize his driving forces: motives, intentions, goals, anxieties. The judgment is based on an analysis of actions, as well as our understanding of the inner world of the consumer. By identifying the causes of certain actions you can plan relations, their form and possibility of success.

The motive of the driving forces of any behavior will suggest the psychic nature and characteristics of the consumer. In the cognitive economy, a mental status of the goods consumer is assessed based on the characteristics of temperament, character, and focus of interests. Of course, this can be assumed with some degree of probability. Consumer observation of various market segments makes it possible to obtain information that may not be known to the object of observation. It suggests that the probability of one or another act of the subject of consumption of the good can be established, which means endowing possible future behavior. Such psychological analysis was proposed in 1977 by L. Ross in the composition of intuitive psychology and its short comments [1].

In this theory of "causal attribution" approaches are proposed to explain the behavior of other people as causal relations. Outwardly similar behavior of consumption subjects can occur for various reasons. So it is necessary to understand that the same motive in different subjects of consumption induces different behaviors, which is caused by both external conditions and various internal (mental) features.

\section{CONCLUSION}

A cognitive approach to the development of human resources for new types of entrepreneurship from the perspective of market foresight demand shows that the statement of the "subject of supply" comes from causal attribution (the presumptive nature of the causes of behavior ). For example, "What would I like as a subject of consumption of goods?" Therefore, there is a psychic projection of the image of some behavior from the available resource of behavior patterns in various situations of different people or the analyst's life experience. There is a combination of the external appearance of the perceived consumer, who makes decisions on the acquisition of the product and the behavior pattern imposed on this consumer, which is usually taken as a template, as well as the accumulated life experience.

\section{ACKNOWLEDGMENTS}

The article was funded by the Russian Foundation for Basic Research "Cognitive approach to theoretical and methodological foundations of strategic development of small businesses in the digital economy system taking drift risks into account" No. 18-010-01210 - A.

\section{REFERENCES}

[1] G. Kh. Brutland, "Our Common Future", Report of the UN Commission on the Environment and Development, M.: Progress, 1988, $50 \mathrm{p}$.

[2] V. T. Chepikov, "Elimination of the negative impact of individual schoolchildren on classmates in the process of moral education", Issues of strengthening the health of the population, theory, methodology and psychophysiology of physical perception and sport: In 2 vols, Cheboksary, 1995, vol. 2, pp. 417-422.

[3] E. Fromm, "Escape from freedom. Man for himself", Erich Fromm; trans. from English, M.: ACT: ACT MOSCOW, 2006, 571 p.

[4] M. Gerber, "Mastery of entrepreneurship: 7 strategic directions for the development of your business", M.: Williams, 2008, 448 p.

[5] S. I. Gryadov, "Theory of Entrepreneurship", M .: Kolos, 2007, 328 p.

[6] H. Heckhausen, "Motivation for achievement", SPb .: Speech, 2001, 238 p.

[7] I. M. Kirtsner, "Competition and Entrepreneurship", Per. with ann., ed. A.N. Romanova, M .: UNITY-DANA, 2001, 239 p.

[8] E. A. Klimenko, "Training of business managers as an element of providing staff for universities of art and culture", Formation of a regional cultural policy in the context of modernization of education: materials of the International Scientific and Practical Conference, Orel, 24-28 March 2014, Eagle: FSBEI HPE Oryol state, Institute of Arts and Culture, 2014, pp. 102-105.

[9] L. A. Mosina, "Development of entrepreneurship in the agricultural sector", Abstract. dis. ... cand. economy Sciences: 08.00.01, N. Novgorod, 1999,19 p.

[10] A. I. Paramonov, "Entrepreneurial training of youth: an innovative educational system (organizational and pedagogical foundations of entrepreneurial training of youth)", M.: KPISTP, 2004, $121 \mathrm{p}$.

[11] V. P. Poznyakov, "Social Psychology of Entrepreneurship: state of research and modern development trends", Social Psychology. Textbook for universities, ed. A. L. Zhuravleva, M .: Publishing house Forum; Infra - M, 2008, pp. 391-408.

[12] V. V. Radaev, "Economic and sociological concepts of human economic behavior: a comparative study", Abstract. dis. ... Dr. Econ. Sciences: 08.00.01; 22.00.03, M., 1997, 27 p.

[13] B. A. Raizberg, L. Sh. Lozovsky, and Ye. B. Starodubtseva, "Modern economic dictionary, 5th ed., Revised. and add., M .: INFRA-M, 2007, $495 \mathrm{p}$.

[14] L. Ross, "The intuitive psychologist and his shortcomings: distortions in the attribution process", Advances in Experimental Social Psychology, In L. Berkowitz (ed.), N.Y., 1977, vol. 10, pp. 174-220.

[15] J. Schumpeter, "Theory of Economic Development", M .: Progress, 1982, 455 p.

[16] A. E. Selivanenko, "Entrepreneur activity in the field of physical culture and sports and the mechanism of its development in market conditions of management", Dis. ... cand. econ. Sciences: 08.00.05, Moscow, 2003, 189 p.

[17] A.V. Shokhnekh, V. S. Telyatnikova, V. L. Pozdeev, A. L. Nosov, and N. S. Mushketova, "Concept Strategy of Innovative Small Business in the System of Economic Security of the Digital Economy", Growth Poles of the Global Economy: Emergence, Changes and Future Perspectives, Series of books: Lecture Notes in Networks and Systems, Cham : Springer, 2020, vol. 73, pp. 1397-1406.

[18] G. I. Sidunova and A. V. Shokhnekh, "Balance-cognitive approach to foresight-development of management audit efficiency digital economic systems in the context of strategic drift", Lecture Notes in Networks and Systems, 2019, vol. 57, pp. 657-665.

[19] V. S. Telyatnikova, A. V. Shokhnekh, V. I. Bespyatykh, M. A. Azarskaya, and O. Yu. Kolyshev, "Approaches to Formation of an Innovative Platform of University Complexes in the Strategy of Human Resources Development as Small Business Entrepreneurs", Growth Poles of the Global Economy: Emergence, Changes and Future Perspectives, Series of books: Lecture Notes in Networks and Systems, Cham : Springer, 2020, vol. 73, pp. 1363-1372. 
[20] O. V. Tokarenko, "Value orientations of Russian entrepreneurship", Author. dis ... cand. economy Sciences: 22.00.03, M., 1998, 26 p.

[21] R. E. Warneryd, "The Psychology of Inovative Entrepreneurship", Handbook of economic psychology, Dodrecht, Netherlands: Kluwer Academic Publishers, 1988, pp. 405-447.

[22] A. L. Zhuravlev and V. P. Poznyakov, "Social Psychology of Russian Entrepreneurship: the Concept of Psychological Relations", M.: Publishing House "Institute of Psychology RAS", 2012, 479 p.

[23] N. G. Yushkova, E. G. Gushchina, and A. V. Shokhnekh, "Spatial location of regional resources within the strategic drift of globalization: problems, tendencies, procedures", $\underline{\text { SHS web }}$ of conferences, 2019, vol. 62. pp. 2-4.
[24] A. F. Rogachev, E. V. Melikhova and A. V. Shokhnekh, "Information technology of cognitive modeling of industrial and investment self-development of the medium-sized and single-industry towns Revista Espacios", 2019, vol. 38 [Electronic resource]. Available at: http://www.revistaespacios.com/a17v38n27/17382704.

[25] A. V. Shokhnekh, N. N. Skiter, A. F. Rogachev, and T. V. Pleschenko, "Features of optimal modeling of tax mechanisms in the leveling system of environmental and food security taking into account inter-industry externalities", J. Environ. Manag. Tourism, 2017, vol. 8 , no. 1 , pp.100-104. 